\title{
EDITORIAL
}

\section{On Becoming a Surgical Intern: Navigating the Lurch from Medical School to Internship}

\author{
Curt Tribble, MD
}

Division of Cardiac Surgery, University of Virginia Health System, Charlottesville, Virginia, USA

\section{INTRODUCTION}

If interns don't say anything, we think they're stupid. When they talk, we know.

There are three major transitions in the educational trajectory of those heading into a career in surgery. The first transition is from the first year or two of medical school to the clerkships of the third year. The second is the transition from medical school into the first postgraduate year of residency training. The third, which is widely held to be the toughest transition of all, is from residency into independent practice. This review, which could be called a "rookie's survival guide," will address the second of those lurches, that of the transition from medical school into a surgical internship.

The Army Rangers are full-on killers. - Heard on ESPN Radio after Pat Tillman's death in Afghanistan

In contrast to the Army Rangers, remember that no matter how uncertain you are about your preparation to be a surgery intern, at the end of this first year of your training you will almost certainly be well on your way to becoming a "full-on healer."

\section{A faculty surgeon only has 20 fuly's in him. -Malcolm Perry, MD}

As a new academic year gets underway, a review of some tips and strategies for new surgical interns to help them in getting off to a good start on that remarkable trajectory seems appropriate. Perhaps some of these suggestions will make that first year a bit easier on the interns and the patients that they care for, as well as on those who teach and supervise them.
Correspondence: Curt Tribble, MD, Professor of Cardiothoracic Surgery, University of Virginia Health System, Division of Cardiac Surgery, Box 800679, Charlottesville, VA 22908; 434-243-9250 (e-mail: ctribble@virginia.edu).
FIRST THINGS FIRST: THE FOURTH YEAR OF MEDICAL SCHOOL

Do an "internship" in your fourth year of medical school, and you will find that being an intern will be considerably easier and less stressful. —Bill Shea, MD, Internal Medicine Resident

The first consideration worthy of note is what the future surgical intern can do while still in medical school to prepare for their impending internship year. Whereas the first three years of medical school are fairly scripted, the fourth year offers at least some opportunity for tailoring one's preparation for internship. There are a number of principles to consider when designing a solid and appropriate fourth year for those heading into surgical residencies. One of these principles should be to make the most of this year, as opposed to the misguided strategy of "resting up" for residency. The prospective surgical intern should attempt to learn as much as possible about the medical conditions that could cause significant problems for their future surgical patients. After all, much of a surgical intern's work will revolve around the medical care of the surgical patient. With this reality in mind, one should consider gaining experience with cardiology, pulmonary medicine, nephrology, and infectious disease. Other rotations that would undoubtedly be valuable include critical care, emergency medicine, and general internal medicine.

Another old adage about preparing for internship is that most medical school graduates are at least somewhat uncomfortable with children and neurological issues. Since one approach to optimizing the fourth year schedule is to line up rotations that will cover two or more priorities at a time, a fourth year student interested in surgery might line up rotations in pediatric surgery and neurosurgery.

Most medical students know, or can find out, who the best teachers in their institution are and try to line up rotations based on that inside knowledge. A thorough discussion of the pro's and con's of doing rotations at other institutions is beyond the scope of this essay, but it is worth noting that the value of such rotations is likely over-rated, and the cost and other potential downsides of doing them are often underestimated. 
Finally, there are a variety of courses and experiences that can supplement the formal clinical rotations, such as Advanced Cardiac Life Support (ACLS), Advanced Trauma Life Support (ATLS), techniques and anatomy courses, and boot camps. The availability of such experiences at one's home institution should be ascertained when planning the fourth year of medical school.

\section{LOOK THE PART}

Patients in an academic medical center generally do not get to choose or approve of all of the physicians who will participate in their care. This reality imposes an additional obligation on all trainees to act professionally and to "look the part." -Phil Lambruschi, MD, Chief Resident in Surgery

Although most medical schools and residency programs do not, at least these days, have strict dress codes, it is certainly important to dress to inspire confidence. As a new surgical houseofficer you should never, ever look disheveled, nor give the appearance of being dazed and confused. It is hard to argue with patients' common assumption that if their surgeon, or their surgeon's team members, are sloppily attired, they may well be sloppy in other ways, such as in the medical and surgical care they provide. Find hair styles that are relatively easy to maintain. Change your clothes if they are soiled or bloody. Many patients disapprove of having their physicians look like they just came in from a jog or from the gym. It is worth paying attention to your name tag, ensuring that it clearly shows your name and your title (ie, MD). And, always remember that you will often represent the entire team, including the attending surgeon. In fact, I have often reinforced this concept by telling my house officers that "I need you to be me."

\section{LEARNING SURGERY ON THE GO (BECAUSE THE DAYS ARE JUST PACKED)}

To achieve great things, two things are needed: a plan and not quite enough time. - Leonard Bernstein, Director of the New York Philharmonic Orchestra

Learning "on the go" as a surgical houseofficer differs significantly from the learning styles and approaches that got you through much of your prior formal education. In fact, the learning strategies that will be necessary when you are a surgical house officer are very different, and they always will be.

If you don't know anything, it is hard to learn anything else. - ED Hirsch, Founder of the Core Knowledge Foundation

There is a grand tradition at some institutions of reading, in its entirety, a basic text in the discipline one will soon be entering during the three months between Match Day and July. Obviously, following this tradition will work best if one chooses a book that can realistically be read in that time. A reasonable choice may be Essentials of General Surgery, edited by Peter Lawrence.
Even though this textbook was originally designed for medical students, it is short enough to be read in its entirety in the months prior to starting the new academic year. Reading such a book will provide a matrix or a base of knowledge that will help make learning new information easier. Having a matrix in which to place new information is a very useful learning strategy. Such a matrix can be thought of as being like mailboxes in a mailroom. Each new concept, principle, or fact learned can be "stored" in these "mailboxes" (Figure 1).

Essentials of General Surgery is available both in a standard format and in electronic formats. One can, of course, dig into a more comprehensive text, but a priority should be placed on choosing a book that you can and will actually read, cover to cover, prior to starting your internship. One technique to make such a plan feasible is to take that textbook to a place like a FedEx Kinkos, and have them cut the back off the book and drill holes in the pages so that the text can be kept in a three ringed binder. Then, a few pages at a time can be taken in and out of the binder and kept in your coat pocket or some other suitable place, with the goal of reading those pages during the "breaks in the action" that are frequently part of even fairly busy days on the wards. You will likely be amazed at how efficiently you can make your way through a book using this approach. Plus, you will avoid the risk of "book apnea," which can occur when you fall asleep with a heavy textbook on your chest.

\section{What Should Be on Your Bookshelf as You Start Your Internship?}

There are a number of books that are worth owning, in one format or another, by surgical residents in the early phase of their training. The first group of books to consider will be those that most surgical residents should read at some point or at least be very familiar with. These essential "classics" include:

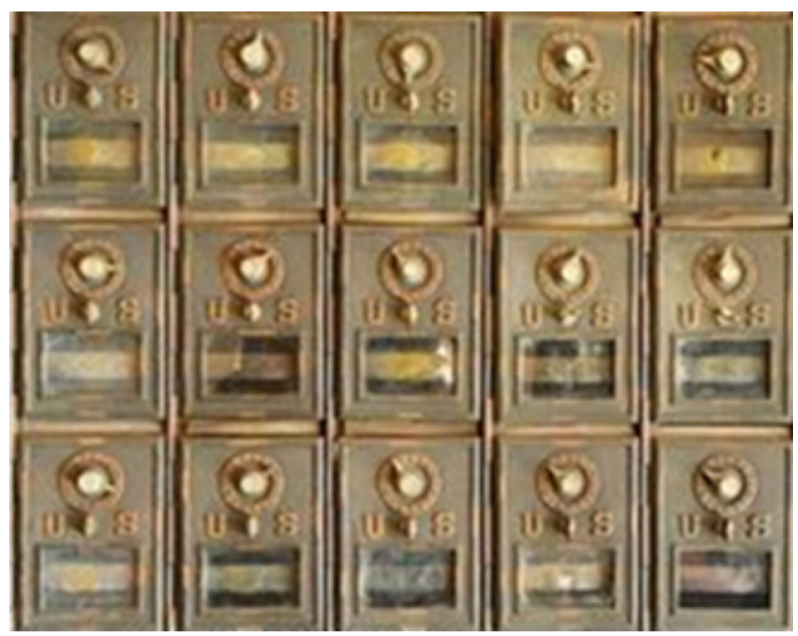

Figure 1: Having a matrix of base knowledge in which to place newly learned information is a useful learning strategy, like storing things in mailboxes in a mailroom. 
- Cameron: Current Surgical Therapy

- Gray \& Skandalakis: Atlas of Surgical Anatomy for General Surgeons

- Silen: Early Diagnosis of the Acute Abdomen

- Elefteriades: The House Officer's Guide to ICU Care

- Pestana: Fluids and Electrolytes in the Surgical Patient

- Dubin: Rapid Interpretation of EKG's

A second group of books were created to help residents prepare for exams, such as the American Board of Surgery InTraining Exam (ABSITE) and the eventual American Board of Surgery Qualifying Exam (the written Board exam). There are a number of popular, up to date, and very useful books of this type, including:

- Blackbourne: Surgical Recall and Advanced Surgical Recall

- Fiser: The ABSITE Review Book

- Porrett \& Drebin: The Surgical Review

When using books of this sort, it is worth remembering the old adage that "the answers may change, but the questions are timeless." Of note, many thoughtful surgical educators believe that the best format for learning from collections of questions is the simple question/simple answer format. Then, one can occasionally practice for the typical multiple choice test format by studying multiple choice questions.

There is a third group of books that could fall in the category of belonging on your bedside table, meaning that they could be glanced at just before settling in for the night. Books in this category could include:

- Anderson \& Romfh: Technique in the Use of Surgical Tools

- Mattox \& Hirschberg: Top Knife

- Meador: A Little Book of Doctor Rules

Many have also found books by or about doctors to be sources of insight and inspiration. Some examples in this category are:

- David Slavitt: Physicians Observed

- Stephen Westaby: Open Heart

- Henry Marsh: Do No Harm

- Paul Kalanithi: When Breath Becomes Air

- William Nolen: The Making of a Surgeon

(But, but, but: avoid the depressing tome, The House of God, by Samuel Shem. Dr. Shem seemed to have despised his medical internship as he never wanted to be a "real doctor," in stark contrast to virtually all surgical interns who do hope to become doctors capable of taking care of the most challenging patients.)

In addition to books such as these, there is value in subscribing to at least a few journals and reading through them regularly. Arnold Relman, a former editor of the New England
Journal of Medicine, used to assert that every physician (even while in medical school) should subscribe to a general medical journal, which seems to be very sound advice. It is rare that an issue of his former journal (or the Journal of the American Medical Association) does not include something of interest to surgeons. There is also similar, and perhaps more apparent, value in subscribing to a surgical journal. The best surgical journal for interns to subscribe to is likely the Journal of the American College of Surgeons. Glancing at these journals will be informative and will keep one aware of issues of current interest to the medical and surgical communities.

You can also sign up to receive the Table of Contents of many, if not most, medical and surgical journals. More often than not, the full articles can be freely accessed through institutional libraries. Furthermore, there is a very useful website called SCI-HUB (https://sci-hub.tw/), through which one can freely access most medical and scientific articles by plugging in the DOI identifying number of the article. You should construct a filing system to save PDF's of key articles in some way, such as on your computer, a portable drive, or with a system such as Dropbox or Evernote.

Another excellent method of learning surgery "on the go" is to find someone at your institution who has purchased the "SESAP Audio Companion," which is available through Oakstone. This system is a set of recorded interviews with experts who discuss the issues covered in the SESAP (Self-Education and Self-Assessment Program) system of the American College of Surgeons, and it is updated regularly. The recordings can be downloaded into iTunes and then transferred to an iPod, which, of course, is a completely mobile learning system, which can be listened to in the car or while working out.

Demand not information, but a way of learning. The real purpose of education is teaching people to teach themselves. - Jacob Neusner, The Social Contract between Students and Teachers

One should always read about the conditions encountered in the day to day care of patients on the services to which you are assigned. And, of course, one should read about each and every operative case in which you are involved.

Another very effective learning strategy is to keep index cards or a small pocket notebook with you at all times and to write down at least one thing each and every day that you will look up at the next available opportunity. The notes that you make about such things can then be shared on rounds the next day. Similarly, you should have a reading plan which ensures that you are able to gradually get through a more advanced text such as Current Surgical Therapy in your first year.

Every residency program has numerous educational conferences. Of course, you should attend as many of these conferences as possible. You will always remember more from such conferences if you take notes. A very effective strategy for taking or making notes has been described as "The 30 
Second Review" [Scott 2015]. The basic strategy is to take 30 seconds, immediately after the conference, to write down the most important points covered. While these notes can be written in a small notebook or on an index card, there is an app for this process, which is called the "30 Second Habit App" (http://www.30secondhabitapp.com/).

Particularly as you become more involved in surgical cases, you should have a Moleskine type notebook in which you can write down your reflections on what you did, what you learned, and what you might want to learn more about, when time permits [Tribble 2016c]. If you are asked a question to which you do not know the answer, you should always say something like "I don't know, but I'll find out," or "I'm here to learn." Remember the old adage that "the next time you see something, what you learned today may save someone's life."

Finally, always remember the old adage that "to teach is to learn twice." Therefore, explaining things about patient care or operative procedures to students, nurses, or other residents will not only be appreciated by those learners, but will also solidify the lessons for you as the teacher.

Even though most interns won't get to operate a lot, you want to be ready to participate in operations when the opportunity arises. One of the oldest adages in surgical training is, "they won't let you operate if you don't know how to tie knots." Therefore, you must practice tying until you are "blue in the face." Some have said that you should have tied over a thousand knots before tying knots in the operating room. One of best ways to practice tying is to carry dental floss around in your pocket. Dental floss is a reasonable facsimile of suture, and the plastic box it comes in makes it easy to carry around. Furthermore, the boxes have small cutters built into them, so the floss will be easy to cut. Best of all, you can buy flavored dental floss, which will make your hands smell good!

Take the initiative to ask your senior residents if you can come to the operating room for components of cases, such as opening and closing. Most senior residents and faculty surgeons will understand that an intern with patient care responsibilities should be allowed to return to the ward after doing an intern level component of a case, rather than remaining in the operating room for the entire case. However, a plan for following this approach should be discussed with your senior resident prior to such cases.

\section{RUNNING YOUR SERVICE}

You want to be the master of the wards, not the befuddled and disheveled master of disaster. - Bill Dion, Senior Surgical Resident

As the intern on most surgical services, your primary role is to ensure that the care of surgical patients is executed in a timely and practical manner. Thus, the intern should be around the patients and should be omnipresent for questions from the nurses and others providing care for the patients. Simply put, you need to show up and be around. Answer all pages as quickly as possible, as the quickest way to annoy your more senior residents is to not answer pages. You must remember that, if you don't answer pages, those who paged you will page those senior residents.

The dullest pencil is sharper than the sharpest intern. - Basil Schaheen, Chief Resident in Surgery

Be on time for morning rounds, since rounds cannot start, at least not efficiently, until the intern is present. Never trust your memory. Write down everything you are told to do as rounds progress. When morning rounds are over and the senior residents have headed to the operating rooms or clinics, set aside some time to yourself, perhaps with a cup of coffee, to rewrite your list. This new list should not be organized by patient or room number, but by task and by priority. At the top of the list, you should list the chores that need to be tended to right away, such as ordering an urgent study. Then, group the other chores by category, such as drains that need to be pulled, procedures that need to be done, calls that need to be made, and notes that will need to be written eventually (More on writing notes later).

Make sure that your list is legible and easy to read. Put open boxes next to each chore, so that you don't have to mark through them, as doing so will preserve the legibility of your notes. Furthermore, there will be some significant satisfaction to be gained from seeing what you have accomplished as your day progresses. As you create this newly organized list, you will often think of things that should be added to it that were not explicitly stated during rounds. As you create your work list, ask yourself each day what lines, tubes, and catheters can be removed.

An important chore that should be on your list each and every day is to review the MAR (Medication Administration Record) for each patient so that you know what medications each of your patients is receiving. You should understand each of these medications, since you are, in essence, each patient's primary doctor. If you are not familiar with a medication, look it up, so that you know the effects, side effects, half-lives, and proper dosages. And, for each medication a patient is receiving, consider if and when it can be stopped, or when an intravenous medication can be converted to an oral form [Meador 1992].

The next objective of your day should be to check in with the nurses on the floor so that you can tell them of the plans that the team has for their patients. Doing this will save you a lot of time by reducing the need for these nurses to page you, and because you will inevitably learn of things that they think need to be tended to. Additionally, whenever a nurse tells you about an issue with a patient, your first response, if you are unsure of what should be done, ought to be to ask "what do you usually do?" 
In your "master list," you will also want to list all of the films and studies that have been ordered for your patients, and you should have the following goals:

- Review the studies as soon as possible after they are completed.

- Look at the studies yourself, in addition to reading interpretations. (You will learn a lot, and since you know the patients, you may see things that the interpreter of the studies missed.)

- Review these studies with someone who is an expert in those studies, if you are unsure of how to interpret them.

- Confirm that the study has actually been done.

Every doctor is a drug. You can bave salutary effects and unintended side effects. Learn the pharmacology of being a doctor. Clifton Meador, MD

Once you have gotten the early part of your day under control, you need to make your own rounds and see each patient under your care. Practice "bed sitting," or taking a relaxed position in the patient's room, avoiding the bad habit of standing at the foot of the bed. Talk to the patients and their families. Not only will you be likely to hear something important, but you will also find that it is fun, and therefore energizing, to get to know your patients better. Always examine "the part that hurts," whatever that may be and pay particular attention to all surgical wounds. You must have a stethoscope and listen to the patient's lungs, heart, and abdomen. However, you do not need a fancy stethoscope. To paraphrase an old saying about cameras, the best stethoscope is the one you have with you all the time. You can (and should) buy the lightest, thinnest stethoscope available, as they are easily carried around even in the back pocket of scrub pants. (However, you should never, ever carry a stethoscope around your neck, as you most certainly do not want to be mistaken for an internal medicine resident.)

Your soul will be enriched by each person you care for. Thomas Nasca, MD, 2018

When talking to your patients, always ask them what they plan to do when they are well again. They will always have an answer to that question, and, much more often than not, a short discussion about their answers will be fun for you and beneficial to the patient [Tribble 2016b].

As the day wears on, remember the following principles:

- Always go see any patient that anyone is concerned about. You will nearly always hear, see, feel, or sense something important.

- Rely on the nurses and ask them for advice.

- Involve your students, as they can often be of considerable help. And, they will appreciate and learn from these experiences. You can describe their involvement as "the main doctor concept."
- Always take any significant concerns "upstairs" by notifying your senior residents or the attendings. They will NEVER fault you for calling too much, but they will fault you for calling too little or too late.

- Lastly, there can be some solace in reminding yourself that the only thing you know for sure each day is that it won't be like you thought it would be.

Take charge of rounds, especially those that occur at the end of the day. Be efficient. Do not speak in abbreviations, as doing so is inefficient and raises the possibility of confusion. Know your patients and pertinent results for the day. Present your patients on rounds in a problem oriented manner (more on this strategy, as it pertains to writing notes, later). Again, if you don't know the answer to a question that arises, always say "I don't know but I'll find out."

Always be sure that you have done a thorough postop check on all patients returning to your care from the operating room. You must understand what was done and what concerns the surgical team has about each postoperative patient. An important principle to keep in mind is that tachycardia is never normal. Do not assume that tachycardia is caused by pain or anxiety, at least not until you have ruled out more serious issues such as blood loss, sepsis, dehydration, or a complication like an anastomotic leak.

Finally, during transitions of care, such as when signing out to a night float resident or when switching services, you need to have an efficient and effective system for informing those who will be covering or taking over what they need to know about the patients on your service. One method that can facilitate this process is the SBAR system. SBAR stands for: situation, background, assessment, and recommendations. Here are suggestions for what to include in these "handoffs:"

- Situation: Reason for admission, and days postop or days in the hospital.

- Background: The patient's problem list.

- Assessment: The patient's condition and issues of concern.

- Recommendations: Issues that will need to be tended to in the near term.

It is generally recommended that a written SBAR overview be created for each patient and passed along to those who will be covering.

Another approach to finishing up your day and preparing for a handoff of care is to ask yourself two general but essential questions:

- What are the health maintenance issues that need to be considered for each patient? (These issues include things like DVT prophylaxis, the treatment of anemia, glycemic control, etc.) 
- What might kill your patient in the next 12 hours? (These issues could include conditions such as a tenuous respiratory situation or ongoing hemodynamic instability.)

\section{ARE YOU MAKING YOURSELF CLEAR?}

Good intelligence depends in large measure on clear, concise writing. The information that the CIA gathers and the analysis it produces mean little if we cannot convey that information effectively. - The CIA Style Manual, 2011

Toward the end of your day, you need to complete a daily progress note. Your notes should be viewed as an important means of conveying to others what you and your team are thinking about and planning for your patients.

\section{I write to find out what I think. —Stephen King}

However, writing notes should not be viewed as merely a perfunctory chore. Rather, the process of writing progress notes should be thought of as an opportunity for you to clear your mind and to think comprehensively about your patients.

While most students are taught to write so-called S.O.A.P. notes, there is a lot of misunderstanding about how to write progress notes properly. The first step in writing a note about a patient is to create a problem list. Then, for each problem, write out the subjective or historical information, followed by the findings from your exam that are related to that problem. After that, you should record the additional objective information you have gathered for that problem. Next, you need to create an assessment of that particular problem, followed by your plan, at least as best you know it at the time. Thus, you should use the S.O.A.P. note approach for each problem, not for each patient.

These notes can be printed out and used both for presenting on rounds and for making notes about ongoing developments as they arise the next day. Then those notes can serve as a template for the notes that you will write the following day. While you may hear that you should not cut and paste notes forward in the medical record, that admonition is incorrect, if you carefully edit and update the cut and pasted note from the prior day.

On a related note, while electronic medical records (EMR) can certainly make information retrieval much easier than was true in the past, they can end up seeming to be the bane of your existence. Besides using templates and other shortcuts, perhaps the most important principle of using the EMR is to avoid, as much as is possible, sitting in front of a computer all day long.

Finally, you will usually be responsible for creating a discharge summary for each patient on your service. These summaries should be created with the goal of informing subsequent providers of what they will need to know to care for the patients when they see the discharged patient. The summaries most certainly should not include long, detailed accounts of every minor event that occurred during the hospitalization. They should detail the primary reason the patient was admitted, any procedures that were done, the status of the patient at the time of discharge, and what the plans are for the coming days and weeks. For instance, if staples were used to close a tenuous wound, a specific note on when they will be removed should be included. All discharge medications need to be listed, and the expected schedule of follow-up for the patient should be made clear. An old rule for discharge summaries likely remains pertinent: any discharge summary, if printed out, should be no longer than two typed pages.

\section{INTERPERSONAL HYGIENE (COMMUNICATING EFFECTIVELY)}

One of biggest challenges of residency, and especially of the early years of training, is how to maintain good relationships with all the various practitioners with whom you will interact on a day to day basis. Some of the most basic advice in this realm for interns or junior residents includes avoiding overstating your role or position in the hierarchy, knowing all about your patients so that you are ready to answer questions posed by patients, their families, the nurses, or consultants seeing your patients, and always asking these people if they have any questions that you might be able to answer. Again, if you don't know the answers to any of these questions, you should always admit that you don't know or are unsure, but you should always say that you will find out.

On a similar note, you should strive to listen more than you talk. A good question to ask yourself with each and every interaction is how you think you will feel about how you handled the situation the next day. Almost always, the answer to that question will be a more favorable one if you maintain a gracious, courteous demeanor.

It's important to remember that there are a lot of smart, caring, committed, and professional healthcare workers who do not have MD degrees. —Georgette Dent, MD

It has been said that people have conversations to accomplish some combination of two goals, which are to exchange information and to manage impressions. Asking good questions will achieve both of those goals [Brooks 2018; Ryan 2017]. Some of the best questions you can ask someone with whom you work are:

- Wait. What?

- Can you help me understand better?

- How can I help?

- What are your primary concerns?

- May I push back on that a bit?

- Could we at least .....? 
There are also ways to disagree while remaining agreeable. Some of the most disarming strategies to help achieve this goal are to:

- Focus on solutions rather than on differences of opinion.

- Let others express their emotions and listen in a nonjudgmental way.

- Listen carefully and repeat the words used by those talking to you.

- Give people positive feedback.

- And, always ask yourself what it is you want to have happen.

It has been said that the most important mind you can change during a conversation is your own. If you set out to win every argument, you will usually alienate people. The "winner" of many arguments will gain little, while the "loser" can end up learning something useful. In other words, you want to learn to argue in ways that build relationships rather than hurting them [Shannon 1976].

In discussions with someone who has more authority than you (which, as an intern, will be almost everyone), try employing one or more of the following tactics:

- Validate the other person's point of view, to show you understand it.

- Explain that you may have a different point of view and ask if you can outline your reasoning.

- Emphasize that you are merely offering your opinion and invite critiques.

- Acknowledge the authority of the person with whom you are talking.

- Always make the patient being discussed the priority rather than your own ego.

- And, a useful and disarming comment that one can make in many discussions is "I am here to learn."

Written communication is difficult to do well, and it can be an especially tough medium for tone. - Walter Klyce

Finally, it is worth remembering that emailing or texting messages about complicated or contentious issues should almost always be avoided, as these means of communicating are best for conveying facts and while being unfavorable for dealing with complex issues. [Klyce 2018]

\section{TAKE CARE OF YOURSELF, BOTH NOW AND} FOR THE REST OF YOUR CAREER

Does how you feel affect the way you perform? - Doug Newburg, $\mathrm{PhD}$

Of course, the answer to this question is that how you feel will affect the way you perform in most realms. The followup to this question is, "How often do people ask if they can help you optimize how you feel?" Because the answer is generally "not very often," managing how you feel day-to-day is primarily your own responsibility [Newburg 2005].

We have written about maintaining health through diet, exercise, clothing, and rest as a busy student or houseofficer. Basically, it is important to realize that actively maintaining your health and fitness during residency, and throughout your career, is not a luxury. It is a necessity [Tribble 2016a]. 1967

I get by with a little help from my friends. - The Beatles,

Another aspect of caring for yourself includes maintaining supportive relationships. Everyone needs friends, and the most accessible ones are often those with whom you are in training. In his book Tribe, Sebastian Junger writes to those who serve in the military, describing the importance of maintaining relationships with those with whom they serve or have served [Junger 2016]. Residency training may not be as demanding as overseas military deployments, but the analogy is certainly apt. Focusing on building relationships with your new colleagues does not require abandoning old friendships. However, in one way or another, many friends and families of surgical house officers will have to realize that they will have less access to you and your attention than they might have had in prior times, at least for a time. Most friends and families will be understanding of your priorities during residency.

Thus, it is worth considering strategies that can help you become more connected to those with whom you are training. One such strategy is to organize dinners at the homes of your residency mates, or to arrange for evenings out for meals or music with them. Often, other inclusive group activities can be organized, such as hiking, biking, or team sports, such as Ultimate Frisbee (which has the advantage of it being likely that few of your peers were professional Frisbee players in their former lives, allowing for a level playing field).

For those with pre-existing relationships, including spouses, it is crucial to help those in your life understand the constraints of your training and the collective investment in the future. While recognizing that residency training is at least a bit of a selfish endeavor, a good piece of advice for those who live with others who are not in medicine is to always strive to do your part with household chores, such as making at least your side of the bed when you leave early in the morning or doing your own laundry [McRaven 2017]. Furthermore, even though some consider it to be a cliché, you must try to make every minute with the significant people in your life be quality time. It is also important to help these people understand that you respect and appreciate their role in supporting your mission of becoming the best physician and surgeon possible [Ricketts 2014].

A useful strategy for many is to keep a daily or weekly log of things that you have done or thought. One example is to keep an exercise log, as doing so will both remind you of what you have actually done, and perhaps inspire you to do a bit more. 
Another idea that has recently been proposed is called "Three Good Things," which suggests that each day you write down three good things, which could be things you learned, things you did, or things you saw that day [Tuma 2017].

\section{NOTES FOR THOSE IN PRELIMINARY (NON- CATEGORICAL) RESIDENCY POSITIONS}

Surgery interns in non-categorical positions are in a precarious situation by definition, and will therefore need to have some approaches and strategies that are somewhat different from interns who have matched into a categorical spot. First of all, it is worth noting that although Plan A will be to obtain a categorical position, either through the Match process or at the institution in which the non-categorical intern is working, the non-categorical intern must also have a Plan B. Such alternate plans may include accepting a second non-categorical year or choosing a different discipline for training, such as Anesthesiology, Emergency Medicine, or Family Medicine. Regardless of how such considerations evolve, non-categorical residents will need to utilize a variety of strategies to optimize their chances of obtaining a position in which they can complete their training in Surgery, or possibly in a different discipline.

Residents in these situations will need to keep up to date all of their documents, such as CV's, and they will need to pay close attention to all application-related deadlines (ERAS, NRMP, etc). Next, they will need to understand that they will need letters of recommendation from those supervising them in their current roles, as most residencies will value these assessments significantly more than assessments or letters from the intern's medical school. Residents can ask more senior residents and faculty members to send notes of support to those who are likely to be writing letters of recommendation for subsequent applications. For those with lower scores on their National Board of Medical Examiners exams, including in their documents the results of all exams they have taken in prior years can be helpful, as good performances on exams such as the SAT, the ACT, and the MEDCAT can demonstrate facility with taking such tests. Furthermore, preparing in order to perform well on the American Board of Surgery In-Training Exam (ABSITE) given each year in January is essential (see the section above on "Learning Surgery on the Go").

Don't you forget about me. - Simple Minds, The Breakfast Club, 1985

It is essential to develop a close relationship with the Program Director (and the Program Coordinator) of the residency that the non-categorical resident is in. These people will almost always feel an obligation to be of help to all of their residents. Emails can work to keep in touch with them, but these emails must be terse and to the point. Using bullet points can help achieve this goal, as they may keep the eyes of the readers from glazing over.
You should be sure that the leaders of the program, as well as the other faculty members, see you as being engaged in all aspects of the training program and the work of the services to which you are assigned. Make an effort to get to clinics, the operating room, and all of the pertinent conferences as much as is practical. Showing up in these arenas not only demonstrates interest, but also maintains awareness of your level of commitment, work ethic, and degree of enthusiasm. You should seek advice from a wide array of the people you work with, including faculty other than the Program Director, senior residents, and even your peers.

What else will you be judged on during your preliminary year or years? You must be reliably and incessantly available to all who supervise you. Be sure that your beeper is always on and that your batteries are charged. You can make yourself even more available by giving your cell phone number to those you work with so that they can text or call you directly. You will also be judged by your appearance and your attitude, so dress professionally at all times and maintain a cheerful demeanor. You will want to do your best to appear interested, poised, professional, and organized. Finally, you can keep your eyes open for an opportunity to contribute to a publication with one of your faculty members, such as a review article or a case report.

\section{CONCLUSIONS}

It's supposed to be hard. If it wasn't hard, everyone would do it. The hard is what makes it great. - A League of Their Own, 1992

Becoming a good intern is challenging but manageable. You must have a plan and not merely wait to be told what to do on a daily basis. There is no reason not to be organized and available. There is no excuse for not "looking the part." And, day by day, your patients are not only your primary responsibility, but they can and should also be a source of inspiration to you.

I believe that man will not merely endure: he will prevail. He is immortal, not because be alone among creatures bas an inexhaustible voice, but because he has a soul, a spirit capable of compassion and sacrifice and endurance. - William Faulkner, Nobel Prize Acceptance Speech, 1950

The vast majority of interns in surgery will find at the end of that first year of residency that they have indeed, not merely endured, but have become "full-on healers" capable of providing excellent medical care to their surgical patients.

\section{ACKNOWLEDGEMENTS}

Many of my current and former students, residents, teachers, and colleagues offered suggestions and advice for this essay. Some were particularly helpful, including Drs. 
John Davis, Basil Schaheen, Hunter Mehaffey, Matt Goldman, Bill Shea, Reid Tribble, Bill Dion, Phil Lambruschi, Clifton Meador, Bradley Rodgers, and Doug Newburg.

A source of inspiration for this essay was a self-published guide for house officers at the University of Virginia which was entitled, "The Unvanquished." Many University of Virginia residents and faculty members contributed to the various iterations of this treatise, which was updated annually for many years.

\section{REFERENCES}

Brooks A, John L. The surprising power of questions. 2018. Harvard Business Review May-June 2018:60-7.

Central intelligence Agency. 2011. Style manual \& writers' guide for intelligence publications. 8th ed. http://www.fas.org/irp/cia/product/ style.pdf Accessed 7-2018.

Junger S. 2016. Tribe: on homecoming and belonging. New York, New York: Hachette Book Group, Inc.

Klyce W. 2018. On breaking bad news. JAMA 320:135-6.

McRaven W. 2017. Always make your bed. New York, New York: Grand Central Publishing, Hachette Book Group.

Meador C. 1992. A little book of doctor rules. St Louis: Hanley \& Belfus.

Newburg D. 2005. The most important lesson no one ever taught me. USA: Xlibris Corporation.

Ricketts A. 2014. No man's war: irreverent confessions of an infantry wife. Berkeley, CA: Counterpoint Press.
Ryan J. 2017. Wait, what? And life's other essential questions. New York, New York: HarperCollins.

Scott R. 2015. The 30-Second Habit with a Lifelong Impact. Observer http://observer.com/2015/08/the-30-second-habit-with-a-lifelongimpact/ Accessed 7-2018.

Shannon JP. 1976. The tradition of respectful argument. In: Varco DL, Delaney JP, eds. Controversy in Surgery. Philadelphia: WB Saunders.

Tribble C. 2016. Always keep your clothes in the car. Heart Surg Forum 19:150-2.

Tribble C. 2016. Gimme three steps. Heart Surg Forum 19:80-1.

Tribble C, Merrill W. 2016. In your own words: toward a more perfect union of patient care and education. Ann Thorac Surg 101:837-40.

Tuma R. 2017. Simple tool shows lasting reduction in burnout. Medscape.

\section{ADDITIONAL RESOURCES}

Edlich R, Tribble C, et al. 2010. Revolutionary advances in the management of traumatic wounds in the emergency department during the last 40 years: Part I. J Emerg Med 38:40-50.

Edlich R, Tribble C, et al. 2010. Revolutionary advances in the management of traumatic wounds in the emergency department during the last 40 years: Part II. J Emerg Med 38:201-7.

Johnson N. 2018. Why it's ok to change your mind. Grist. https://grist. org/article/why-its-ok-to-change-your-mind-from-a-former-anti-gmoactivist/ Accessed 7-12-18.

Tribble C. 2016. A practical minded obsession. Heart Surg Forum $19: 1-4$.

Tribble C, Merrill W. 2014. How We Talk is the Way We Teach. J Thorac Cardiovasc Surg 147:1155-9. 